Check for updates

Division of Infection and Global Health Research, School of Medicine University of St Andrews, St Andrews, UK

2 Department of Epidemiology, Johns Hopkins School of Public Health, Baltimore, MD, USA

3 Division of Biosciences, University College London, London, UK

4 Department of Primary Care and Public Health, Brighton and Sussex Medical School, Brighton, UK

Correspondence to: M Cevikmc349@st andrews.ac.uk

Cite this as: BMJ2021;372:n224 http://dx.doi.org/10.1136/bmj.n224 Published: 27 January 2021

\section{Support for self-isolation is critical in covid-19 response}

\author{
Government action needed now to reduce infections and deaths \\ Muge Cevik, ${ }^{1}$ Stefan D Baral, ${ }^{2}$ Alex Crozier, ${ }^{3}$ Jackie A Cassell ${ }^{4}$
}

The resurgence of covid-19 in the autumn of 2020 in many northern countries, including the UK, has been associated with tremendous morbidity and mortality. Before vaccination, the public health response focused on testing and population-wide restrictions, with the goal of decreasing contact between susceptible and contagious individuals. Striking and widening disparities in covid-19 related outcomes have highlighted the intersection of socioeconomic disadvantage and health inequalities, enhanced by structural racism. ${ }^{1-4}$ Socioeconomically disadvantaged and many ethnic minority groups have been disproportionately affected, with increased risk of infection, hospital admission, and death. ${ }^{5-8}$

Despite the vaccine rollout, many younger people, particularly those working in high exposure occupations, living in overcrowded housing, or without a home will remain subject to an ongoing burden of quarantine orders, along with a disproportionate risk of infection and onward transmission for the foreseeable future. ${ }^{159} \mathrm{An}$ equitable and effective public health response requires the integration of supportive services to effectively decrease their contact rates and subsequently risk of infection. ${ }^{9}$

Most countries have used testing as a tool to interrupt transmission chains by encouraging isolation of contacts. However, the ability to quarantine until test results are available, and to isolate if positive, depends on people having the space and resources to do so. ${ }^{10}$ Survey data from the UK suggest that less than one in five people are able to adhere to isolation protocols. ${ }^{11}$ Notably, lower rates of adherence have been reported among men, younger people, key workers, those living with dependent children, and those in lower socioeconomic groups. ${ }^{11}$ Although willingness to self-isolate was high across all respondents, the self-reported ability to isolate was three times lower among those earning less than £20 ooo ( $€ 23$ 00o; \$27 000) a year or who had less than £10o saved. ${ }^{12}$ This finding is consistent with reports that lost wages are the primary reason for not following isolation guidelines. ${ }^{10}$

The risk of household transmission within crowded and otherwise inadequate housing intersects with financial barriers to isolation and inability to work from home. Office of National Statistics data show those living in six person households were three times more likely than two person households to be infected. ${ }^{5}$ Furthermore, crowded households are often multigenerational family groups, including people in high exposure occupations and vulnerable older people..$^{813}$ A large proportion of people living in socioeconomically deprived areas have unpaid caring responsibilities, linking households and enhancing transmission risk. ${ }^{13}$

The highest covid-19 mortality has been observed in facility based outbreaks, including in long term care facilities, retirement homes, and homeless shelters. ${ }^{1415}$ Staff in long term care and similar occupations are low paid, often on zero hours contracts, and typically share the prevalence patterns of the communities at greatest risk of covid-19. ${ }^{15}$

Since the landmark principles of a population screening test were first set out by Wilson and Jungner in 1968, it has been accepted that the usefulness of screening tests is determined by the effectiveness of the intervention they trigger. ${ }^{16}$ What interventions can justify covid-19 screening tests, given the barriers to self-isolation faced by those at highest risk of a positive result?

\section{Appropriate support}

Several well described models have been shown to enhance compliance with quarantine and isolation. Fundamental components include ensuring financial security and compensation as well as practical support. A test-and-care model in San Francisco, US, addressed many of the logistical and financial barriers to self-isolation faced by socioeconomically vulnerable populations through provision of information about community resources, home deliveries of material goods (groceries, personal protective equipment, and cleaning supplies), and clinical and social support for people with positive results. ${ }^{17}$

Not only was the intervention feasible and acceptable, with $67 \%$ of participants requesting support to self-isolate, but trust in the scheme improved over time. This resulted in $11 \%$ of participants disclosing a larger number of contacts than at first reported, and $7 \%$ requesting temporary relocation to a hotel room for isolation despite initially declining this service.

A similar scheme in New York City offers people with positive results a menu of supportive services to help them quarantine either at home or in free hotel accommodation. ${ }^{18}$ The service includes free deliveries of food and medicines, transport, and even dog walking. Vermont designed a response with the needs of high risk groups in mind and has generally had low community spread compared with other US states. Its community and public health led scheme includes protection from eviction, state supported housing for homeless people, hazard pay, meal deliveries, and free pop-up testing in high risk communities. ${ }^{19}$ These interventions have led to high rates of test uptake, number of contacts identified, and adherence to self-isolation, contributing to 
reducing total household and community transmission. ${ }^{10}$

As vaccines are rolled out, even small improvements in people's ability to quarantine and isolate can have an important effect on slowing transmission, hospital admission, and death, especially among those most at risk of covid-19. ${ }^{10} 20$ The next phase of the public health response must align testing strategies with people's lived realities and establish a readily accessible scheme that provides free and safe accommodation for those in need as well as adequate income support, job protection, and replacement of caring responsibilities.

Ultimately, people need to be able to isolate without fear of a substantial damage to their work, income, family, or caring responsibilities. We can't wait for vaccine mediated decreases in morbidity and mortality to manifest. Too many lives have been lost or destroyed. Integrating equitable support services for those most at risk for covid-19 is a national emergency and governments should act accordingly.

Competing interests: We have read and understood BMJ policy on declaration of interests and declare MC is a co-opted member of NERVTAG advising SAGE, JC is a member of social care working group advising DHSC and SAGE.

Provenance and peer review: Commissioned; not externally peer reviewed.

1 Cevik M, Marcus JL, Buckee C. Smith TC. SARS-CoV-2 transmission dynamics should inform policy. Clin Infect Dis 2020:ciaa1442. doi: 10.1093/cid/ciaa1442 pmid: 32964919

2 Rodriguez-Diaz CE, Guilamo-Ramos V, Mena L, etal. Risk for COVID-19 infection and death among Latinos in the United States: examining heterogeneity in transmission dynamics. Ann Epidemiol 2020;52:46-53.e2. doi: 10.1016/j.annepidem.2020.07.007 pmid: 32711053

3 Office for National Statistics. Deaths involving COVID-19 by local area and socioeconomic deprivation: deaths occurring between 1 March and 31 May 2020. 2020

https://www.ons.gov.uk/peoplepopulationandcommunity/birthsdeathsandmarriages/deaths/bulletins/deathsinvolvingcovid19bylocalareasanddeprivation/deathsoccurringbetween1marchand31may2020 2020 July 21.

4 Okonkwo NE, Aguwa UT, Jang M, etal. COVID-19 and the US response: accelerating health inequities. BMJ Evid Based Med 2020:bmjebm-2020-111426; [Epub ahead of print.] doi: 10.1136/bmjebm-2020-111426. pmid: 32493833

5 Public Health England Transmission Group. Factors contributing to risk of SARS-CoV2 transmission in various settings. 2020. https://www.gov.uk/government/publications/phe-factors-contributingto-risk-of-sars-cov2-transmission-in-various-settings-26-november-2020

6 Rose TC, Mason K, Pennington A, etal. Inequalities in COVID19 mortality related to ethnicity and socioeconomic deprivation.medRxiv 2020:2020.04.25.20079491. [Preprint.] doi: 10.1101/2020.04.25.20079491

7 Lone NI, McPeake J, Stewart NI, etal. Influence of socioeconomic deprivation on interventions and outcomes for patients admitted with COVID-19 to critical care units in Scotland: a national cohort study. Lancet Regional Health-Europe, 2020. [Epub ahead of print.], doi: 10.2139/ssrn.3705271.

8 Sundaram ME, Calzavara A, Mishra S, etal. The individual and social determinants of covid-19 in Ontario, Canada: a population-wide study.medRxiv 2020:2020.11.09.20223792. [Preprint.]

9 Link BG, Phelan J. Social conditions as fundamental causes of disease. J Health Soc Behav 1995;(Spec No):80-94. doi: 10.2307/2626958 pmid: 7560851

10 SPI-B. Impact of financial and other targeted support on rates of self-isolation or quarantine 2020. https://assets.publishing.service.gov.uk/government/uploads/system/uploads/attachment_data/file/925133/S0759_SPI-B_The_impact_of_financial_and_other_targeted_support_on_rates_of_self-isolation_or_quarantine_.pdf

11 Smith LE, Potts HWW, Amlot R, etal. Adherence to the test, trace and isolate system: results from a time series of 21 nationally representative surveys in the UK (the COVID-19 Rapid Survey of Adherence to Interventions and Responses [CORSAIR] study).medRxiv 2020:2020.09.15.20191957. [Preprint.] doi: 10.1101/2020.09.15.20191957

12 Atchison C, Bowman LR, Vrinten C, etal. Early perceptions and behavioural responses during the COVID-19 pandemic: a cross-sectional survey of UK adults. BMJ Open 2021;11:e043577. doi: 10.1136/bmjopen-2020-043577 pmid: 33397669

13 SAGE. Housing, household transmission and ethnicity: For SAGE meeting 26 November 2020. https://www.gov.uk/government/publications/housing-household-transmission-and-ethnicity26-november-2020

14 Guenther T. Czech-Sioli Manja, Indenbirken Daniela, et al. Investigation of a superspreading event preceding the largest meat processing plant-related SARS-Coronavirus 2 outbreak in Germany.SSRN 2020. [Preprint.] doi: 10.2139/ssrn.3654517

15 Wang L, Ma H, Yiu KCY, etal. Heterogeneity in testing, diagnosis and outcome in SARS-CoV-2 infection across outbreak settings in the Greater Toronto Area, Canada: an observational study. CMAI Open 2020;8:E627-36. . doi: 10.9778/cmajo.20200213 pmid: 33037070
16 Wilson JG, Jungner G. Principles and practices of screening for disease. 1968. https://apps.who.int/iris/bitstream/handle/10665/37650/WHO_PHP_34.pdf?sequence=17

17 Kerkhoff AD, Sachdev D, Mizany S, etal. Evaluation of a novel community-based covid-19 'test-to-care' model for low-income populations. PLoS One 2020;15:e0239400. . doi: 10.1371/journal.pone.0239400 pmid: 33035216

18 New York City Take Care. 2020 https:/www.nychealthandhospitals.org/test-and-trace/take-care/

19 Sosin A, Carpenter-Song E, Griffin M, O'Reilly M. Housing is health: building on Vermont's pandemic success to advance health equity. 2021. https://www.hereruralequity.com/january-2021-brief.

20 Benfer EA, Vlahov D, Long MY, etal. Eviction, health inequity, and the spread of covid-19: housing policy as a primary pandemic mitigation strategy. J Urban Health 2021. doi: 10.1007/s11524-020-00502-1 pmid: 33415697

This article is made freely available for use in accordance with BMJ's website terms and conditions for the duration of the covid-19 pandemic or until otherwise determined by BMJ. You may use, download and print the article for any lawful, non-commercial purpose (including text and data mining) provided that all copyright notices and trade marks are retained. 